\title{
Judgments about the duration of brief stimuli*
}

\author{
LORRAINE G. ALLAN and A. B. KRISTOFFERSON \\ McMaster University, Hamilton, Ontario, Canada
}

\begin{abstract}
Visual duration discrimination data for durations between 70 and 1,020 msec are presented. A model for duration discrimination proposed by Allan, Kristofferson, and Wiens (1972) is elaborated, and the data are discussed in terms of the model. The data are in agreement with the basic assumptions of the model. Differences between our data and duration discrimination data presented by others are discussed.
\end{abstract}

Allan, Kristofferson, and Wiens (1971) proposed a decision theory model for duration discrimination, the onset-offset model, which specifies that the $O$ discriminates between a longer and a shorter duration stimulus by using the available temporal information rather than other information sources, such as brightness or loudness, which may sometimes be available to him. Since duration has to be marked by energy signals, it is conceivable that in many situations the 0 bases his discrimination between two different durations on some aspect of the stimulus other than its duration. For example, it could be argued that since changes in the duration of a brief flash result in changes in the apparent brightness of the flash, it is possible that when Os are asked to discriminate between brief light flashes of different duration, but equal luminance, their discriminations are based on apparent brightness rather than on duration. If the $\mathrm{O}$ is basing his discrimination on the difference in apparent brightness between a short stimulus, $S_{1}$ of duration $d_{1}$ and a long stimulus, $S_{2}$ of duration $d_{2}$, then decreasing the luminance of $S_{2}$ should result in decreased discrimination. However, if he is basing his discrimination on the difference in duration between the two stimuli, a decrease in the luminance of $\mathrm{S}_{2}$ should not affect the discrimination between the two stimuli. Allan et al (1971) varied the luminance of $S_{2}$ $(15,13$, or $11 \mathrm{fL})$ while keeping $S_{1}$ fixed at $15 \mathrm{fL}$. The duration of $S_{2}$ was $120 \mathrm{msec}$ and the duration of $S_{1}$ was $100 \mathrm{msec}$. They found that the variations in discriminability as a function of luminance difference, $\Delta \mathrm{I}$, were small for all five $\mathrm{Os}$, and not systematically related to changes in $\Delta \mathrm{I}$. Averaged over the five $\mathrm{Os}$, the probability of a correct response, $\mathrm{P}(\mathrm{C})$, was $.83, .83$, and .84 for $\Delta \mathrm{I}$ equal to 0,2 , and $4 \mathrm{fL}$, respectively. On the other hand, when both $d_{2}$ and $d_{1}$ were $100 \mathrm{msec}$, that is, when the difference in duration was $0 \mathrm{msec}$, discriminability increased as a function of $\Delta \mathrm{I}$ for all Os. Thus, discriminable changes in the luminance of $S_{2}$ did not affect the duration discrimination function.

Similarly, Abel (1972a), Creelman (1962), and Henry (1948) have demonstrated that, for brief auditory intervals filled with noise or pure tones, changes in amplitude do not affect discrimination performance, as

*This research was supported by Grants A8260 and A7919 from the National Research Council of Canada. long as the stimulus whose duration is to be judged is easily detectable. In sum, the available visual and auditory data for filled intervals are in agreement with a model for duration discrimination which represents the $\mathrm{O}$ as basing his decision on the temporal information available in the stimulus rather than on other cues which may also be available.

Allan et al (1971), using brief durations in the 50-150-msec range, found that often the O's ability to discriminate between two durations which differed by $\Delta d \mathrm{msec}$ was independent of the absolute duration values. On the basis of these data, they proposed a decision theory model which states that, over a range of duration values, the variability in the internal durations, which is produced by repeated presentations of a stimulus of fixed duration, is independent of stimulus duration. The model specifies that all of the variability in the internal durations is the result of variations in the times, with respect to stimulus time, at which the internal durations begin and end. For any stimulus duration, $d_{i}$, the perceptual onset and offset latencies are each independently uniformly distributed over a range of $\mathrm{q}$ msec. This results in a triangular distribution of internal durations, $f_{i}(i)$, spanning $2 q \mathrm{msec}$, which has a mean equal to the physical duration of the stimulus, and a variance $\left(\mathrm{q}^{2} / 6\right)$ which is independent of stimulus duration. These distributions are illustrated in Fig. 1 for two durations, $d_{j}$ and $d_{k}$, where $d_{k}>d_{j}$. The 0 is represented as adopting a criterion internal duration, $\mathrm{C}$. If an internal duration is greater than $C$, the $O$ responds long, $R_{L}$; otherwise he responds short, $R_{S}$. The model predicts that an $O$ 's ability to discriminate between two durations depends only on the difference between the two durations, $\Delta \mathrm{d}$, and is independent of their durations. Specifically, the difference between the means of the two distributions is $d_{q}$

$$
\mathrm{d}_{\mathrm{q}}=\frac{\Delta \mathrm{d}}{\mathrm{q}}
$$

where $d_{q}$ is a criterion-free discriminability measure. Equation 1 specifies that the measure $d_{q}$ is the distance in $q$ units between the means of $f_{j}(I)$ and $f_{k}(I)$

$$
d_{q}=Q\left(R_{L} \mid S_{j}\right)-Q\left(R_{L} \mid S_{k}\right)
$$




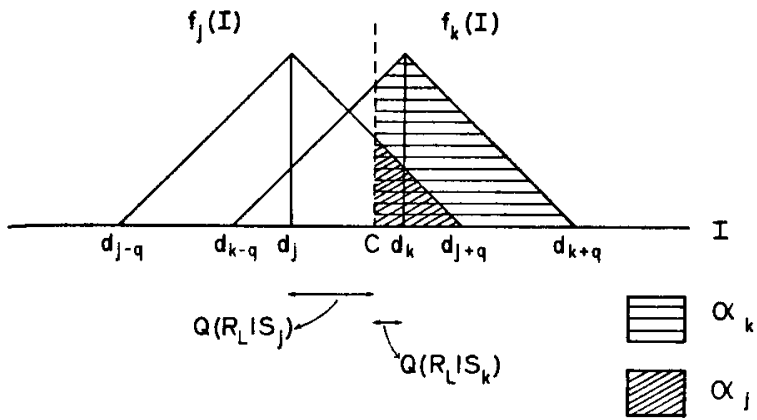

Fig. 1. The O's decision problem in the onset-off set model.

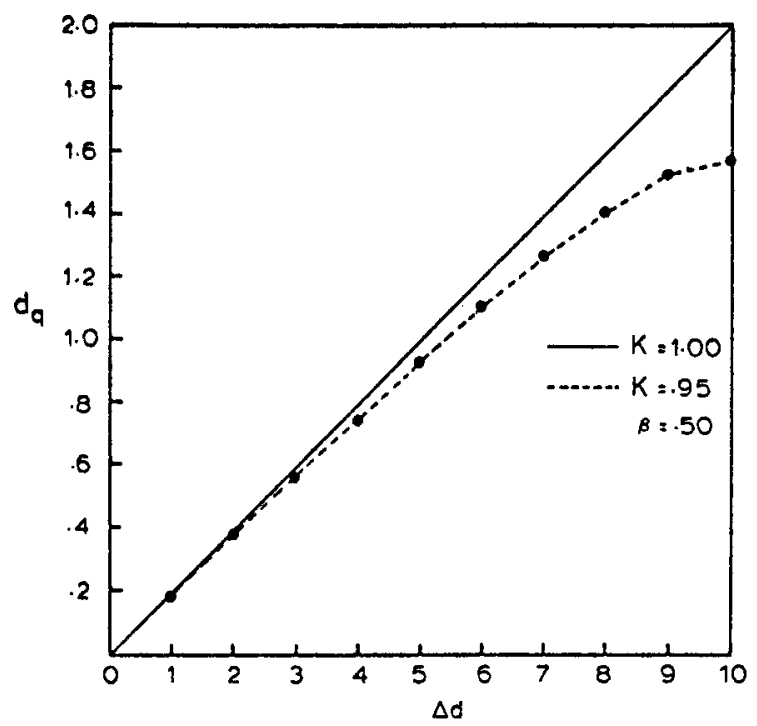

Fig. 2. The $d_{q}$ vs $\Delta d$ function for two values of $K, 1.00$ and .95 , and $\beta=.50$.

where $Q\left(R_{L} \mid S_{j}\right)$ and $Q\left(R_{L} \mid S_{k}\right)$ are the distance in units of $q$ from the criterion to the mean of the $f_{j}(I)$ and $f_{k}(I)$ distributions, respectively. That is, $Q\left(R_{L} \mid S_{i}\right)$ is that value of $I$, in units of $q$, which is exceeded with probability $\alpha_{i}$, where

$$
\alpha_{i}=\int_{C}^{d_{i}+q} f_{i}(I) d I
$$

In summary, the model specifies that the ability to discriminate between two durations, expressed in terms of $d_{q}$, increases as a zero intercept linear function of the duration difference between them, for $0 \leqslant \mathrm{~d}_{\mathrm{q}} \leqslant 2$, and is independent of the absolute value of the two durations.

Baron (1969) has also suggested that the time between the occurrence of a stimulus and its perception is variable. However, he assumed that the distribution of these times was normal. A normal assumption about perceptual onset and offset latencies would result in a normal rather than a triangular distribution of internal durations. It is extremely difficult to distinguish between the two distributions on the basis of discrimination data. In the Allan et al (1971) paper, we gave one reason for our preference for assuming uniform perceptual latency distributions over normal distributions. In essence, our theorizing about successiveness discrimination and discriminative reaction time is more closely related to the uniform perceptual latency distribution than to the normal. This relationship has since been discussed by Kristofferson and Allan (1973) and by Kristofferson (1973). The reader is referred to these papers for greater detail.

Allan et al (1971) reported duration discrimination data for duration stimuli between 50 and $150 \mathrm{msec}$. The operating characteristic (OC) curves generated from the data of three Os suggested that the internal durations evoked by a brief light flash could be approximated by a triangular distribution whose variance was independent of the duration of the flash. In general, $d_{q}$ was directly proportional to the duration difference between the two stimuli, and for six of the nine Os was independent of stimulus duration. In general, the onset-offset model provided a reasonable account of the data.

In the present paper, we present visual duration discrimination data for a greatly extended range, for durations between 70 and $1,020 \mathrm{msec}$. Our major interest is in examining the relationship between the variability in internal durations produced by a stimulus and its duration value. In particular, we were interested in determining whether the independence of variability of stimulus duration would be observed over a range larger than $100 \mathrm{msec}$.

In our studies on duration discrimination, we have repeatedly observed that, while the $\mathrm{d}_{\mathbf{q}}$ vs $\Delta \mathrm{d}$ function is linear for values of $d_{q}$ less than about 1.50 , it often tends to deviate from linearity, by bending downwards, for larger values of $d_{\mathbf{q}}$. In Fig. 2, we illustrate what would happen to the $d_{q}$ function if the $O$ did not have any stimulus information on $5 \%$ of the trials and made an $R_{L}$ response with probability .50 on these trials. Anyone who has served as an $O$ in a psychophysical experiment knows that on some trials the response is independent of the stimulus, because the stimulus was not "processed." Specifically, consider the diagram in Fig. 3. When a stimulus, $S_{i}$, is presented, the $O$ enters a process state, $\mathrm{p}$, with probability $\mathrm{K}$, and a nonprocess

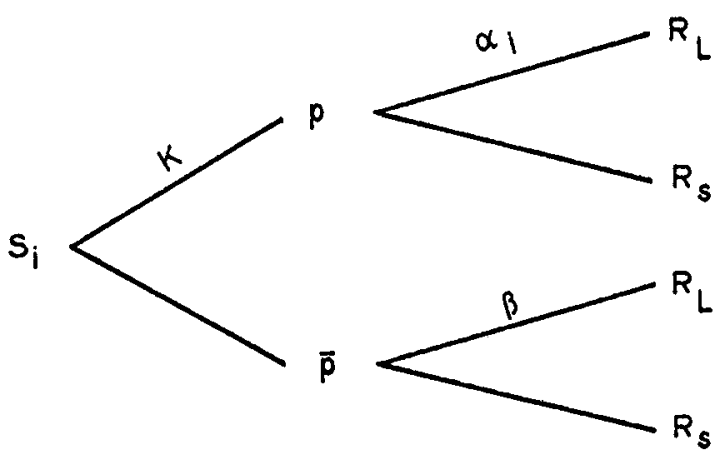

Fig. 3. Schematic of the model. 
6.

Fig. 4. The $O$ 's decision problem for $N=$

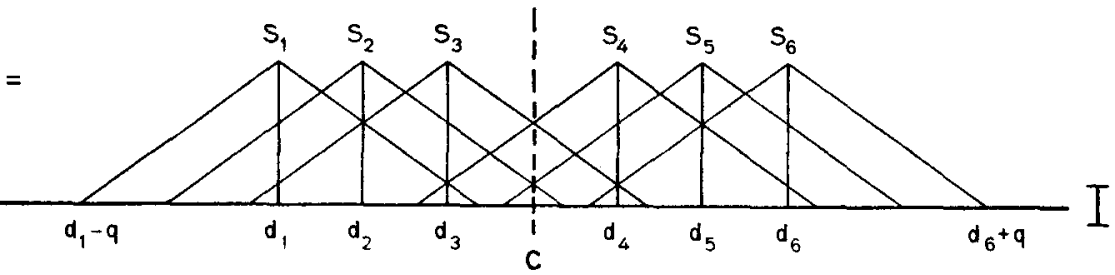

state, $\overline{\mathrm{p}}$, with probability $(1-\mathrm{K})$. In a $\overline{\mathrm{p}}$ state, the $\mathrm{O}$ guesses and makes a $R_{L}$ response with probability $\beta$. In a p state, the $O$ makes a $R_{L}$ response with probability $\alpha_{i}$, where $\alpha_{i}$ is as defined in Eq. 3. Thus,

$$
\mathbf{P}\left(R_{L} \mid S_{i}\right)=K \alpha_{i}+\beta(1-K) .
$$

Note that $P\left(R_{L} \mid S_{i}\right)$, the probability of a long response given a particular stimulus, is obtained from the data, and $\alpha_{i}$ represents the probability that the internal duration produced by Stimulus $S_{i}$ is greater than the criterion, $C$. Only when $K=1$ is $P\left(R_{L} \mid S_{i}\right)=\alpha_{i}$.

Figure 2 is the case in which, for each value of $\Delta d$, the criterion is placed midway between the means of the $f_{j}(I)$ and $f_{k}(I)$ distributions. The solid line illustrates the manner in which $d_{q}$ varies with changes in $\Delta d$ when $K=$ 1 and therefore $P\left(R_{L} \mid S_{i}\right)=\alpha_{i}$ (the condition discussed by Allan et al, 1971). The dashed line represents the relationship for $\mathbf{K}=.95$ and $\beta=.50$. For $K \neq 1$, $P\left(R_{L} \mid S_{i}\right)$ is no longer a good estimate of $\alpha_{i}$ (see Eq. 4). The dashed line in Fig. 2, relative to the solid line, illustrates the error in $d_{q}$ resulting from using $P\left(R_{L} \mid S_{i}\right)$ as an estimate of $\alpha_{\mathrm{i}}$ when $\mathrm{K}=.95$ and $\beta=.50$. Missing the stimulus on $5 \%$ of the trials causes the $d_{q}$ function to progressively deviate from linearity with increasing $\Delta d$. It is clear that it would be useful to be able to obtain estimates of $K$ and $\beta$.

The second purpose of the present paper is to describe an experimental procedure which allows estimates of $\mathrm{K}$ and $\beta$ to be obtained. These estimates can then be used to "correct" $P\left(R_{L} \mid S_{i}\right)$ according to Eq. 4 , so that $\alpha_{i}$ can be isolated. The procedure is a modification of the single-stimulus task, and we refer to it as the many-to-few procedure.

On each trial, one of a set of $\mathrm{N}$ possible duration stimuli is presented to the 0 , where $\mathrm{N}$ is an even integer and $N \geqslant 4$. The $O$ is required to make one of two responses, short $\left(R_{S}\right)$ or long $\left(R_{L}\right)$. The $N$ values are symmetrically arranged around some midpoint or center duration, $d_{c}$, and feedback is presented on each trial, mapping $R_{S}$ onto the $N / 2$ shortest durations and $R_{L}$ onto the $N / 2$ longest durations. The outer members of the stimulus set (the shortest, $d_{1}$, and the longest, $d_{N}$ ) must be far enough apart so that neither produces a distribution of I which overlaps the criterion. If the distribution generated by a stimulus does not overlap the criterion, the $O$ should always make a correct response to that stimulus. Any observed errors can be considered the result of missing or not processing the stimulus.

The O's decision problem is presented schematically in Fig. 4 for $N=6$. For the shortest stimulus $\left(S_{1}\right)$, the true probability of an error $\left(\alpha_{1}\right)$ is zero. Substituting $\alpha_{1}=0$ in Eq. 4 yields

$$
P\left(R_{L} \mid S_{1}\right)=\beta(1-K) .
$$

For the longest stimulus $\left(S_{N}\right)$, the true probability of a correct response $\left(\alpha_{N}\right)$ is one. Substituting $\alpha_{N}=1$ in Eq. 4 yields

$$
P\left(R_{L} \mid S_{N}\right)=K+\beta(1-K) .
$$

Expressions for $K$ and $\beta$ can be obtained from Eqs. 5 and 6.

$$
\begin{gathered}
K=P\left(R_{L} \mid S_{N}\right)-P\left(R_{L} \mid S_{1}\right), \\
\beta=\frac{P\left(R_{L} \mid S_{1}\right)}{1-P\left(R_{L} \mid S_{N}\right)+P\left(R_{L} \mid S_{1}\right)} .
\end{gathered}
$$

Thus, if $S_{1}$ and $S_{N}$ are selected so that the distributions of internal durations generated by the stimuli do not overlap the criterion, then $P\left(R_{L} \mid S_{1}\right)$ and $P\left(R_{L} \mid S_{N}\right)$ can be used to estimate $K$ and $\beta$. These estimates can then be used to correct $P\left(R_{L} \mid S_{i}\right)$, for $i=2$ to $N-1$, and an estimate of $\alpha_{i}$ obtained for each of them.

The visual duration discrimination data to be reported below were collected using the many-to-few procedure.

\section{METHOD}

The $O$ sat in an IAC sound-attenuated, dimly illuminated auditory chamber, approximately $66 \mathrm{~cm}$ from the visual display. The visual display consisted of a glow modulator bulb (Sylvania R1131C) driven by an Iconix power supply (Model 6195-4). The bulb was enclosed in a metal box with an aperture of $4 \mathrm{~mm}$ in diam subtending a visual angle of $21 \mathrm{~min}$. The aperture was covered on the inside with a Kodak No. 96 neutral density 2.00 filter and then translucent milk glass. The luminance of the display was $50 \mathrm{fL}$ (150 UB PhotoResearch photometer). The presentation and timing of the stimuli and the recording of the responses were under the control of a PDP-8/E computer.

Each trial began with a $500-\mathrm{msec} 1,000-\mathrm{Hz}$ warning signal. Two seconds later, the display was illuminated for $d_{i}$ sec. The $O$ was then given $2.5 \mathrm{sec}$ to indicate his response, long $\left(R_{L}\right)$ or short $\left(R_{S}\right)$, by pushing one of two buttons on the arm of his chair. On trials where one of the longest $N / 2$ of the stimuli were presented, a $100-\mathrm{msec} 500-\mathrm{Hz}$ tone was presented at the end of the response period. On the remaining trials, no tone was presented. The next trial began $1.6 \mathrm{sec}$ after the end of the response period.

Each daily session consisted of three blocks of 96 trials, with a 1 -min rest interval between blocks. During each block of trials, each of the $\mathrm{N}$ duration stimuli was presented equally often. The 
Table 1

$P\left(R_{L} \mid S_{n}\right), \alpha_{n}$, and $Q\left(R_{L} \mid S_{n}\right)$ for Each Observer

\begin{tabular}{|c|c|c|c|c|c|c|c|c|c|c|c|}
\hline \multicolumn{6}{|c|}{ O W.K. } & \multicolumn{6}{|c|}{ O L.A. } \\
\hline $\mathrm{d}_{\mathrm{c}}$ & Sessions & $\mathrm{d}_{\mathrm{n}}$ & $P\left(R_{L} \mid S_{n}\right)$ & $\alpha_{\mathbf{n}}$ & $Q\left(R_{L} \mid S_{n}\right)$ & $\mathrm{d}_{\mathbf{c}}$ & Sessions & $\mathrm{d}_{\mathrm{n}}$ & $P\left(R_{L} \mid S_{n}\right)$ & $\alpha_{n}$ & $\mathrm{Q}\left(\mathbf{R}_{\mathbf{L}} \mid \mathbf{S}_{\mathbf{n}}\right)$ \\
\hline 740 & 20 & $\begin{array}{l}630 \\
670 \\
710 \\
770 \\
810 \\
850\end{array}$ & $\begin{array}{l}.021 \\
.080 \\
.232 \\
.702 \\
.895 \\
.967\end{array}$ & $\begin{array}{l}.00 \\
.062 \\
.223 \\
.720 \\
.924 \\
1.00\end{array}$ & $\begin{array}{r}1.00 \\
.65 \\
.33 \\
-.25 \\
-.61 \\
-1.00\end{array}$ & 740 & 20 & $\begin{array}{l}630 \\
670 \\
710 \\
770 \\
810 \\
850\end{array}$ & $\begin{array}{l}.075 \\
.196 \\
.377 \\
.735 \\
.891 \\
.966\end{array}$ & $\begin{array}{l}.071 \\
.197 \\
.384 \\
.755 \\
.916 \\
.994\end{array}$ & $\begin{array}{r}.62 \\
.37 \\
.12 \\
-.30 \\
-.59 \\
-.89\end{array}$ \\
\hline 570 & 20 & $\begin{array}{l}460 \\
500 \\
540 \\
600 \\
640 \\
680\end{array}$ & $\begin{array}{l}.00 \\
.021 \\
.222 \\
.858 \\
.975 \\
1.00\end{array}$ & $\begin{array}{l}.00 \\
.021 \\
.222 \\
.858 \\
.975 \\
1.00\end{array}$ & $\begin{array}{r}1.00 \\
.79 \\
.33 \\
-.46 \\
-.78 \\
-1.00\end{array}$ & 740 & 10 & $\begin{array}{l}600 \\
630 \\
670 \\
710 \\
770 \\
810 \\
850 \\
880\end{array}$ & $\begin{array}{l}.006 \\
.056 \\
.122 \\
.361 \\
.717 \\
.833 \\
.967 \\
.972\end{array}$ & $\begin{array}{l}.00 \\
.052 \\
.120 \\
.367 \\
.736 \\
.856 \\
.995 \\
1.00\end{array}$ & $\begin{array}{r}1.00 \\
.68 \\
.51 \\
.14 \\
-.27 \\
-.46 \\
-.90 \\
-1.00\end{array}$ \\
\hline 910 & 20 & $\begin{array}{r}800 \\
840 \\
880 \\
940 \\
980 \\
1020 \\
\end{array}$ & $\begin{array}{l}.004 \\
.071 \\
.259 \\
.738 \\
.908 \\
.987 \\
\end{array}$ & $\begin{array}{l}.00 \\
.068 \\
.259 \\
.747 \\
.920 \\
1.00 \\
\end{array}$ & $\begin{array}{r}1.00 \\
.63 \\
.28 \\
-.29 \\
-.60 \\
-1.00 \\
\end{array}$ & 570 & 20 & $\begin{array}{l}460 \\
500 \\
540 \\
600 \\
640 \\
680 \\
\end{array}$ & $\begin{array}{l}.033 \\
.105 \\
.328 \\
.728 \\
.891 \\
.975 \\
\end{array}$ & $\begin{array}{l}.00 \\
.076 \\
.313 \\
.738 \\
.911 \\
1.00\end{array}$ & $\begin{array}{r}1.00 \\
.61 \\
.21 \\
-.28 \\
-.58 \\
-1.00\end{array}$ \\
\hline \multicolumn{6}{|c|}{ O F.V. } & \multicolumn{6}{|c|}{ O D.A. } \\
\hline 100 & 19 & $\begin{array}{r}70 \\
85 \\
115 \\
130\end{array}$ & $\begin{array}{l}.003 \\
.036 \\
.930 \\
.992\end{array}$ & $\begin{array}{l}.00 \\
.033 \\
.937 \\
1.00\end{array}$ & $\begin{array}{r}1.00 \\
.74 \\
-.65 \\
-1.00\end{array}$ & 570 & 20 & $\begin{array}{l}460 \\
500 \\
540 \\
600 \\
640 \\
680\end{array}$ & $\begin{array}{l}.004 \\
.075 \\
.279 \\
.704 \\
.908 \\
.962\end{array}$ & $\begin{array}{l}.00 \\
.074 \\
.287 \\
.731 \\
.944 \\
1.00\end{array}$ & $\begin{array}{r}1.00 \\
.62 \\
.24 \\
-.27 \\
-.67 \\
-1.00\end{array}$ \\
\hline 200 & 21 & $\begin{array}{l}170 \\
185 \\
215 \\
230\end{array}$ & $\begin{array}{l}.003 \\
.106 \\
.844 \\
.972\end{array}$ & $\begin{array}{l}.00 \\
.106 \\
.868 \\
1.00\end{array}$ & $\begin{array}{r}1.00 \\
.54 \\
-.49 \\
-1.00\end{array}$ & & & & R.H. & & \\
\hline 150 & 12 & $\begin{array}{l}120 \\
135 \\
165 \\
180\end{array}$ & $\begin{array}{l}.006 \\
.067 \\
.910 \\
.980\end{array}$ & $\begin{array}{l}.00 \\
.063 \\
.928 \\
1.00\end{array}$ & $\begin{array}{r}1.00 \\
.65 \\
-.62 \\
-1.00\end{array}$ & 100 & 20 & $\begin{array}{r}70 \\
85 \\
115 \\
130\end{array}$ & $\begin{array}{l}.017 \\
.108 \\
.963 \\
.986\end{array}$ & $\begin{array}{l}.00 \\
.094 \\
.976 \\
1.00\end{array}$ & $\begin{array}{r}1.00 \\
.57 \\
-.78 \\
-1.00\end{array}$ \\
\hline 400 & 20 & $\begin{array}{l}340 \\
370 \\
430 \\
460\end{array}$ & $\begin{array}{l}.00 \\
.150 \\
.889 \\
.983\end{array}$ & $\begin{array}{l}.00 \\
.152 \\
.904 \\
1.00\end{array}$ & $\begin{array}{r}1.00 \\
.45 \\
-.56 \\
-1.00\end{array}$ & 200 & 13 & $\begin{array}{l}170 \\
185 \\
215 \\
230\end{array}$ & $\begin{array}{l}.040 \\
.240 \\
.968 \\
.965\end{array}$ & $\begin{array}{l}.00 \\
.216 \\
1.00 \\
1.00\end{array}$ & $\begin{array}{r}1.00 \\
.34 \\
-1.00 \\
-1.00\end{array}$ \\
\hline
\end{tabular}

same set of $\mathrm{N}$-duration values was presented for a number of sessions before a new set of $\mathrm{N}$ values was introduced.

Data from five Os will be reported. The number of sessions for each set of $\mathrm{N}$ stimuli and the duration values used are presented in Table 1. For those Os who were exposed to a number of stimulus sets, the order of presentation is as listed in Table 1.

\section{THEORETICAL ANALYSIS AND DISCUSSION}

For each $O$ and each stimulus set $P\left(R_{L} \mid S_{n}\right)$, for $n=$ $1,2, \cdots \mathrm{i}, \cdots \mathrm{N}$, was determined on the basis of the last five sessions. These probabilities are presented in Table 1. For each stimulus set, $K$ and $\beta$ were determined using $P\left(R_{L} \mid S_{1}\right)$ and $P\left(R_{L} \mid S_{N}\right)$ according to Eqs. 5 and 6. For each of the other members of the set, $\alpha_{n}$ was determined using Eq. 4. $Q\left(R_{L} \mid S_{n}\right)$ was then determined for each value of $\alpha_{n}$. In Table 1 , values of $\alpha_{n}$ and $\mathrm{Q}\left(\mathrm{R}_{\mathrm{L}} \mid \mathrm{S}_{\mathbf{n}}\right)$ are available.
For O L.A., $d_{c}=740 \mathrm{msec}$, the values of $P\left(R_{L} \mid S_{1}\right)$ and $P\left(R_{L} \mid S_{6}\right)$ obtained from Sessions 16.20 suggested that the internal duration distributions, $f_{1}(I)$ and $f_{6}(I)$, overlapped the criterion and that these values should not be used to estimate $K$ and $\beta$. The range of duration values was extended for the next 10 sessions, two stimuli, 600 and $880 \mathrm{msec}$, being added. The parameters $\mathrm{K}$ and $\beta$ were estimated on the basis of these stimuli (Sessions 26-30), and used to correct both sets of data for $d_{c}=740 \mathrm{msec}$.

In Fig. 5, $Q\left(R_{L} \mid S_{n}\right)$ is plotted as a function of $d_{n}$ for each value of $d_{c}$ for Os W.K., L.A., and D.A. According to the model, this function should be linear for $-1 \leqslant$ $Q\left(R_{L} \mid S_{n}\right) \leqslant 1$. For each set of stimuli, the best fitting straight line was determined for the $\mathrm{N}-2$ inside values. The parameter, $q$, is the reciprocal of the slope of the function, and $C$ is equal to that value of $d_{n}$ for which 

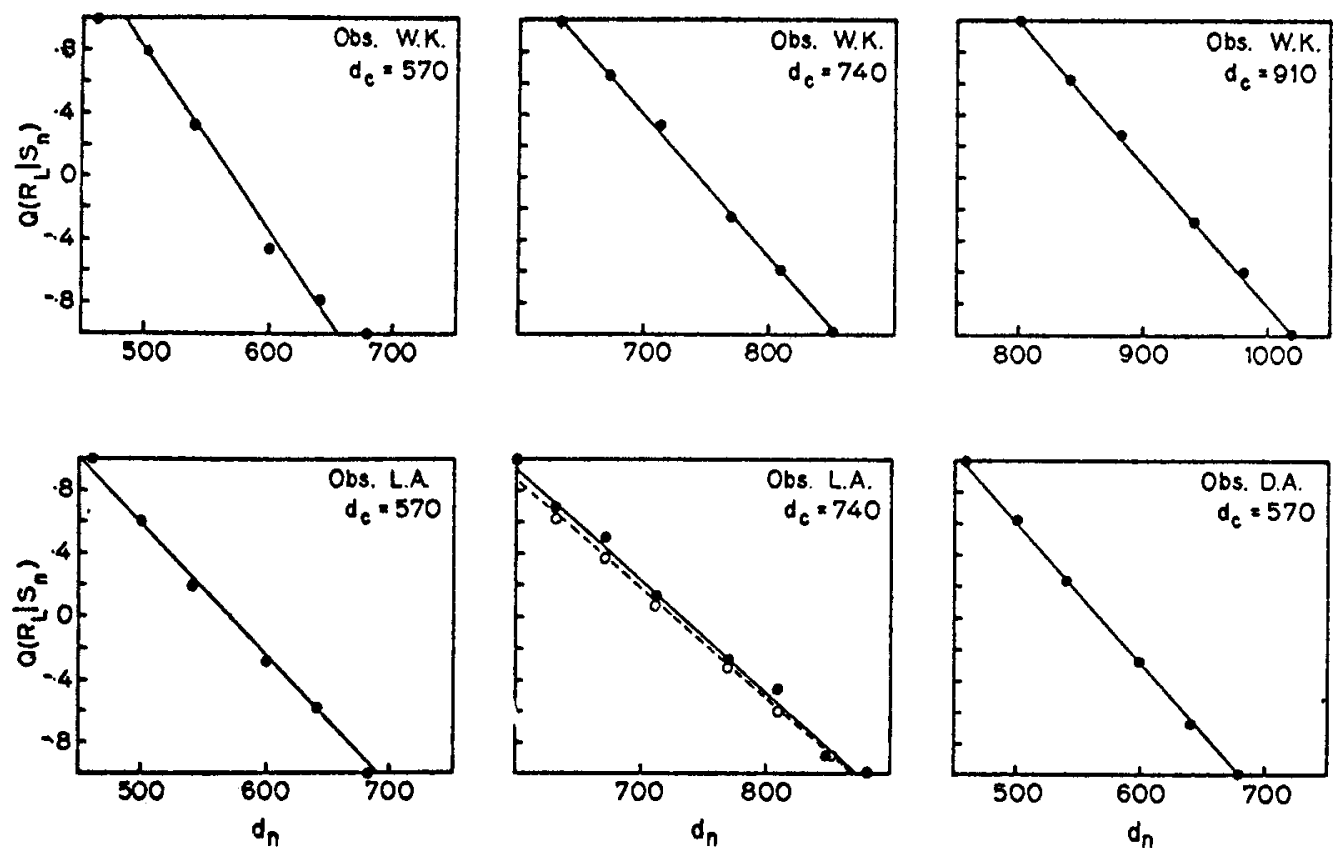

Fig. 5. $Q\left(R_{L} \mid S_{n}\right)$ as a function of $d_{n}$ for each $O$ under each condition.

Table 2

Estimates of $\mathbf{q}, \mathbf{C}, \mathrm{K}$, and $\beta$ for Each Observer

\begin{tabular}{cccccc}
\hline $\mathrm{O}$ & $\mathrm{d}_{\mathbf{c}}$ & $\mathrm{q}$ & $\mathrm{C}$ & $\mathrm{K}$ & $\beta$ \\
\hline W.K. & 570 & 87 & 568 & 1.00 & - \\
& 740 & 110 & 743 & .946 & .389 \\
& 910 & 112 & 910 & .983 & .235 \\
L.A. & 570 & 118 & 570 & .942 & .569 \\
& 740 & 141 & 733 & .966 & .176 \\
& 740 & 145 & 723 & .966 & .176 \\
D.A. & 570 & 110 & 568 & .958 & .095 \\
F.V. & 100 & 22 & 101 & .989 & .273 \\
& 150 & 24 & 150 & .974 & .231 \\
& 200 & 29 & 201 & .969 & .097 \\
& 400 & 59 & 397 & .983 & .00 \\
R.H. & 100 & 22 & 98 & .969 & .548 \\
& 200 & 22 & 193 & .925 & .533 \\
\hline
\end{tabular}

$Q\left(R_{L} \mid S_{n}\right)=0$. The values of the four parameters, $K, \beta$, $\mathrm{q}$, and $\mathrm{C}$, are indicated in Table 2 for each stimulus set. It is clear that a linear relationship between $Q\left(R_{L} \mid S_{n}\right)$ and $d_{n}$ provides an excellent representation of the data. This implies that $q$ is constant for a given stimulus set, and that for each value of $d_{c}$ the variability of internal durations generated by each member of the set is the same.

Figure 6 is a composite of the data in Fig. 5. For each stimulus set, each of the $\mathrm{N}-2$ inside values was standardized with respect to $d_{c}$ in units of $q$, and $Q\left(R_{L} \mid S_{n}\right)$ is plotted as a function of these standardized duration values. The line is the best-fitting straight line to the 32 data points. Again, the linearity of the relationship is clear.

For Os R.H. and F.V., $d_{q}$ was determined for each stimulus set from the two inside values according to Eq. 2. Estimates of the four parameters, q, C, K, and $\beta$, are presented in Table 2 .

In the original formulation of the model (Allan et al, 1971), it was specified that variability and therefore $q$ was independent of stimulus duration over certain stimulus ranges. The data we have just discussed clearly indicate that $\mathrm{q}$ is often constant over large changes in stimulus duration. For O R.H., the estimate of $q$ is constant at $22 \mathrm{msec}$ over the entire range of duration

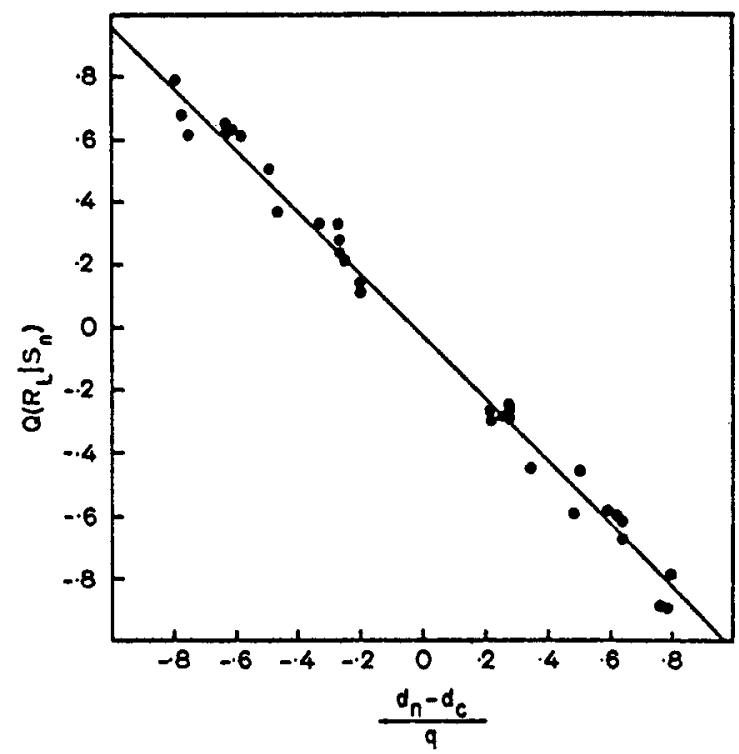

Fig. 6. $Q\left(R_{L} \mid S_{n}\right)$ as a function of $d_{n}$ standardized with respect to $q$. 

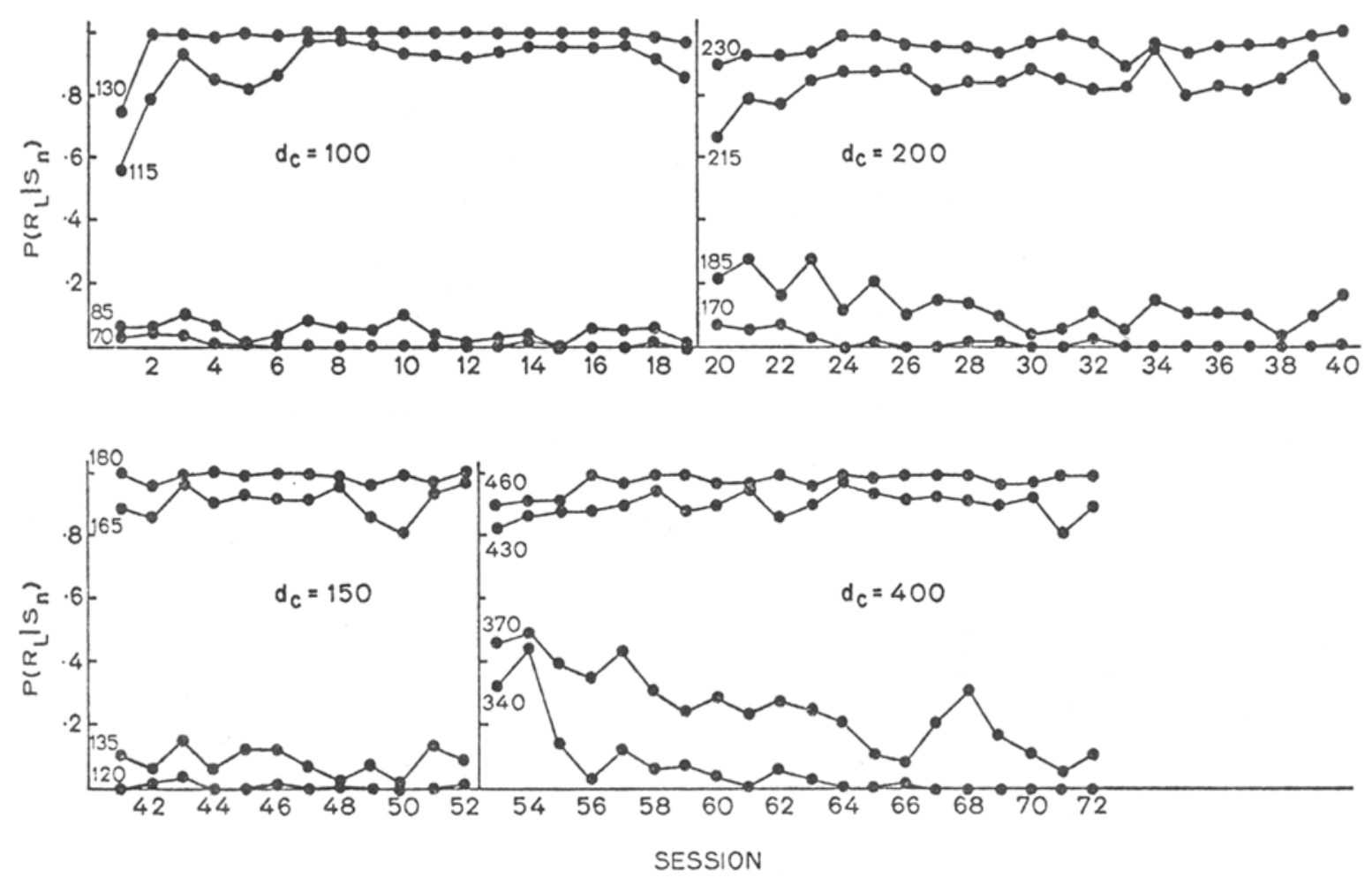

Fig. 7. $P\left(R_{L} \mid S_{n}\right)$ as a function of session number for $O F . V$.

values tested, from 70 to $230 \mathrm{msec}$. Within the context of the model, this means that the variability $\left(\mathrm{q}^{2} / 6\right)$ in internal durations generated by an external stimulus of duration $d_{i}$ is constant for duration values between 70 and $230 \mathrm{msec}$. For OW.K., q is constant at about $111 \mathrm{msec}$ for duration values ranging from 630 to $1,020 \mathrm{msec}$. For stimuli between 460 and $680 \mathrm{msec}, \mathrm{q}$ is $87 \mathrm{msec}$. For OF.V., $\mathrm{q}$ is fairly constant at about $25 \mathrm{msec}$ for duration values ranging from 70 to $230 \mathrm{msec}$. For stimuli between 340 and $460 \mathrm{msec}$, q is $59 \mathrm{msec}$.

It should also be noted that the value of $q$ associated with a stimulus of duration $d_{i}$ depends upon the duration values of the other stimuli within this set. For example, from W.K.'s data, it is clear that for stimuli between 630 and $680 \mathrm{msec} q$ is $110 \mathrm{msec}$ when $d_{c}=$ $740 \mathrm{msec}$ and $\mathrm{q}$ is $87 \mathrm{msec}$ for $\mathrm{d}_{\mathrm{c}}=570 \mathrm{msec}$.

Kristofferson (1973) has presented similar data, concerning the relationship between $q$ and stimulus duration, for empty auditory intervals ranging from 100 to $1,400 \mathrm{msec}$. In sum, the data reported in the present paper, the data reported by Kristofferson (1973), and the original data reported by Allan et al (1971) indicate that the distributions of internal events can be closely approximated by the triangular distribution, that the means of these distributions are directly proportional to stimulus duration within a stimulus set, and that the variability is constant over very large variations in stimulus duration.
Our results appear to be in conflict with duration discrimination data from other laboratories (for example, Abel, 1972a, b; Creelman, 1962). It is usually reported that for a fixed difference in duration between two stimuli, discriminability is a monotonic decreasing function of stimulus duration. Thus, if these other data are conceptualized in terms of a decision theory model, they imply that variability is a monotonic increasing function of stimulus duration. We have found that the amount of practice an $\mathrm{O}$ has with a particular set of duration values is a critical variable. Inexperienced Os always yield functions which show discriminability to be a monotonic decreasing function of stimulus duration. Highly practiced Os often yield functions which show discriminability to remain constant over a wide range of duration values. In Fig. $7, P\left(R_{L} \mid S_{n}\right)$ is presented as a function of session number for OF.V. It is clear that errors decrease dramatically with practice and equally clear that there is considerably less than perfect transfer of the practice effect from one stimulus set to another. This means that the discriminability vs stimulus duration function is likely to be very different for different experimental designs.

The results presented here indicate two directions for future research. It is important to establish the manner in which variability changes with variations in stimulus duration. Over what ranges of durations is the variability constant? Does the size of the range change as one moves from very brief stimuli to longer stimuli, and by 
how much does the variability change when it does change? We are presently engaged in attempting to answer these questions for light flashes, empty auditory intervals, and empty invervals marked by a light at the onset and a tone at the offset.

The second direction is concerned with developing a more adequate theoretical account of duration discrimination. In our original model, we specified that all of the variability in the internal durations was the result of variability in the perceptual onset and offset latencies, and that the variability in these latencies was independent of stimulus duration. This independence appears to be true over a large range of stimulus durations. However, the dependence that is observed as one moves from one stimulus range to another would imply, within that theory, that the variability in the perceptual onset latency of a stimulus is a function of stimulus duration. This is not a very likely possibility. An alternative is to postulate that the variability represented by the triangular distribution is part of the criterion mechanism. We are pursuing that alternative, among others.

\section{REFERENCES}

Abel, S. M. Duration discrimination of noise and tone bursts. Journal of the Acoustical Society of America, 1972a, 51, 1219-1223

Abel. S. M. Discrimination of temporal gaps. Journal of the Acoustical Society of America, 1972b, 52, $519-524$.

Allan, L. B., Kristofferson, A. B., \& Wiens, E. W. Duration discrimination of brief light flashes. Perception \& Psychophysics, 1971, 9, 327-334.

Baron. J. Temporal ROC curves and the psychological moment. Psychonomic Science, 1969, 15, 299-300.

Creelman, C. D. Human discrimination of auditory duration. Journal of the Acoustical Society of America, 1962, 34. 582-593.

Henry, F. M. Discrimination of the duration of a sound. Journal of Experimental Psychology, 1948, 38, 734-743.

Kristofferson. A. B. Psychological timing mechanisms. Paper presented at the Fourth Annual Meeting of the Lake Ontario Vision Establishment. Niagara Falls. Ontario, 1973.

Kristofferson, A. B.. \& Allan, L. G. Successiveness and duration discrimination. In S. Kornblum (Ed.), Attention and performance IV. New York: Academic Press, 1973. Pp. 737-749.

(Received for publication August 20, 1973; revision received December $11,1973$. 